\title{
3 APUNTES PRELIMINARES \\ 3 PARA DESANDAR LOS \\ Melina Chechele RASGOS IDENTITARIOS DE TRABAJO SOCIAL
}

RESUMEN

El contenido de la publicación involucra los avances producidos en el marco de la tesina de grado "Identidad Profesional de Trabajo Social. Abordaje de sus principales rasgos según las miradas de estudiantes de la Licenciatura en Trabajo Social de Santa Fe".

La pregunta rectora de dicho trabajo que refiere a ¿cuáles son los rasgos identitarios de la profesión Trabajo Social reconocidos por los y las estudiantes? dirige la mirada hacia los y las estudiantes avanzados de la Licenciatura en Trabajo Social, de la Universidad Nacional del Litoral de Santa Fe, en el año 2016.

En esta propuesta se plantean algunos elementos para conceptualizar la identidad y sus anclajes en la singularidad de la profesión y en la formación profesional.

A su vez, se presentan algunas reflexiones preliminares surgidas de la construcción que se ha elaborado sobre los rasgos identitarios de la profesión, a partir del cruce de los relevos teóricos y del análisis del material empírico obtenido de los cuestionarios autoadministrados y las entrevistas no directivas.

PALABRAS CLAVE

Trabajo Social; Identidad; Identidad Profesional; Formación; Profesión

\section{ABSTRACT}

This publication's content the progress that has been produced within the degree thesis: "Professional Identity of Social Work. Approach of its main features according to the prospects of the students of the Degree in Social Work, in Santa Fe".

The guiding question of this work refers to: what are the identity traits of Social Work recognized by the students? Looking towards on undergraduate students of the Universidad Nacional del Litoral. Santa Fe, in 2016.

Therefore this proposal includes some elements to conceptualize the identity and their anchors in the singularity of the profession and in the professional formation.

Finally, some preliminary reflections that have been elaborated on the identity features of the profession, starting from the crossing of the theoretical relays and the analysis of the empirical material obtained from self-administered questionnaires and non-directive interviews are presented.

\section{KEY WORDS}

Social Work; Identity; Professional Identity;

Professional Formation; Profession 


\section{Acerca de la noción identidad}

La cuestión identitaria en Trabajo Social constituye una apuesta teórico-epistemológica que atraviesa históricamente la profesión y su construcción disciplinar.

En tal sentido, de inicio resulta necesario introducir algunas consideraciones sobre el propio término «identidad».

Teresa Matus ${ }^{1}$ se vale de los aportes de la filosofía, antropología y sociología, para señalar las distintas acepciones acerca de la noción de identidad. La autora señala dos posturas que ya podían encontrarse en el pensamiento filosófico griego. Refiere a un modo de pensar "esencialista», donde la identidad está en alguna parte, su ser es esencial, ente cerrado, acabado, separado de otro. Se expresa la supremacía del uno sobre lo múltiple, lo cual conlleva la lógica de repetición por el miedo a la «desviación social». La otra perspectiva se funda en la raíz filosófica de Heráclito, en la que el «ser»

está en movimiento. De allí, la identidad es comprendida desde una noción tensional de mediación entre unidad y multiplicidad; por tal es una tarea a construir, es un constante devenir.

Stuart Hall, ${ }^{2}$ analiza las críticas provenientes de variadas áreas disciplinares respecto del concepto de identidad. Ubicado en la perspectiva deconstructivista, ${ }^{3}$ propone pensar la identidad en tanto concepto de difícil reemplazo pero en su forma destotalizada. Plantea que las identidades nunca son singulares, por el contrario, son las posiciones que el sujeto está obligado a asumir sabiendo que son representaciones, y que la representación está construida a partir de una «falta», de la exclusión desde el lugar del otro. ${ }^{4}$

Situado en el mismo encuadre interpretativo que el autor antes citado, Claude Dubar ${ }^{5}$ entiende que la identidad es resultado de un proceso de «identificación contingente» basado en una doble operación lingüística

1 MATUS, Teresa, "Reflexiones en torno a una Ética de la Intervención Social" en Perspectivas, № 9, 2000, ps. 17- 32. UCSH. Santiago, Chile.

2 HALL, Stuart "¿Quién necesita ‘identidad`?" en HALL, Stuart, DU GAY, Paul (comp.) Cuestiones de

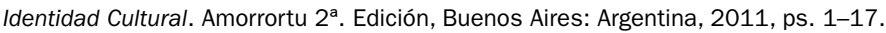

3 La crítica constructivista coloca a los conceptos claves en una posición de ser borrados para pensarlos en su forma destotalizada o deconstruida a cómo fueron generados. De allí, se concibe que la identidad es una idea que no puede seguir siendo pensada como antes, pero sin la cual, ciertas cuestiones claves no pueden ser pensadas. (HALL. 2011:2).

4 HALL, Stuart. Op. Cit. p. 5.

5 DUBAR, Claude, La crisis de las identidades. La interpretación de una mutación, Ediciones Bellaterra, España, 2002. 
de diferenciación y generalización. La primera tiende a marcar la diferencia, la singularidad de algo o de alguien en relación con otros. La generalización alude a la pertenencia común en una serie de elementos diferentes de otros. El nexo común entre ambas operaciones es «la identificación de y por el otro». De allí que no hay identidad sin alteridad.

A su vez, para Francois Dubet ${ }^{6}$ la construcción de la identidad es inseparable de una concepción sociológica del sujeto. Con lo cual no está dada, ni es unidimensional, sino que es resultado del trabajo de un actor que administra y organiza las diversas dimensiones de su experiencia social y de sus identificaciones.

Siguiendo los argumentos de los autores, las identidades se comprenden en relación con los recursos de la historia, el lenguaje y la cultura en el proceso de devenir más que con el del ser. Stuart Hall resume que no se trata de "quiénes somos», "de dónde venimos», sino más bien qué podríamos ser, cómo hemos sido representados y cómo esto tiene que ver con nuestra propia representación. ${ }^{7}$

Las perspectivas consideradas conducen a comprender la noción de identidad distante del esencialismo propio de las concepciones del sujeto de la modernidad, para ser comprendidas en su carácter relacional, contingente, contradictorio, inestable y conflictivo.

Esta propuesta se inscribe en esa clave interpretativa, que da lugar a la idea de "lo identitario» como construcción y movimiento. Lo que también supone diálogo con la otredad, desde un contexto histórico y temporo-espacialmente situado en el que subyacen experiencias y narrativas mediadas por representaciones e identificaciones no exentas de los juegos de poder que, a su vez, operan a través de la diferencia, estableciendo límites y demarcaciones simbólicas defiendo exclusiones y pertenencias.

\section{De profesiones e identidades}

En sintonía con la perspectiva asumida al inicio, por la cual se entiende la identidad como experiencia histórica y social, a continuación se aborda conceptualmente la referencia hacia las profesiones.

6 DUBET, Francois, "De la sociología de la identidad a la sociología del sujeto" en Estudios sociológicos, VII, N²1, 1989, ps. 519- 545. Traducción Francisco Zapata.

7 HALL, Stuart. Op. Cit. p. 4. 
Claude Dubar plantea que los campos con mayor significación para la construcción de identidades profesionales son la formación y el empleo. ${ }^{8}$ Para hablar de identidades profesionales en el caso específico de la profesión Trabajo Social resulta preciso contemplar las implicancias que estas esferas conllevan en el entramado de su singularidad; ya que en lo que respecta al ámbito de formación existe una importante heterogeneidad, en Argentina inclusive, lo cual excluye cualquier posibilidad de generalización.

En relación con esa consideración, Nidia Aylwin, ${ }^{9}$ quien entiende que las profesiones construyen su historia a partir del trabajo que realizan en la sociedad, identifica que algunos rasgos «atribuidos» al Trabajo Social en ese campo refieren a un papel "conciliador», ideológicamente "neutro», "paternalista» y "desposeído de verdadero instrumental científico de interpretación». Según la autora, dicho pragmatismo profesional ha sido reforzado desde la denominada concepción aséptica-tecnocrática, ${ }^{10}$ y agudizado por la Iglesia, el sector privado y el Estado. No obstante, reconoce su reconstrucción desde la propia profesión, dado que las condiciones político-sociales del país no alcanzaban un nivel que permitiera a una profesión romper con el sistema.

En diálogo con estos aportes, desde el recuento histórico que realiza Estela Grassi ${ }^{11}$ se visualiza cómo las funciones «atribuidas» a las labores de las/los asistentes sociales se vinculaban con las concepciones acerca de la asistencia social; entendida ésta como una «obra de defensa de la sociedad», cuyos objetivos eran la moralización, la corrección y la vigilancia de todos aquellos sectores sociales cuya condición era vista como "germen de delito". En ese entramado, la presencia de la mujer asumía una dimensión privilegiada. Por lo que, es posible aseverar, los rasgos atribuidos al rol profesional también se correspondían con las representaciones sociales de los géneros.

Véase DUBAR, Claude en MACHUCA BARBOSA, Adriana "La identidad profesional de los sociólogos. Una perspectiva teórico-metodológica" en MACHUCA BARBOSA, Adriana La identidad profesional de los sociólogos (tesis de maestría) Sede Académica Flacso, México, 2008, p. 53.

9 AYLWIN, Nidia, "Identidad e historia profesional" en Revista Colombiana de Trabajo Social, № 13 , 1999, ps. 1-12. Disponible en: http://www.ts.ucr.ac.cr/binarios/congresos/reg/slets/slets016-103.pdf [búsqueda del 28 de noviembre de 2016].

10 Desde esta concepción se ha caracterizado al Trabajo Social como práctica tradicional mimética y repetidora, reducida a una posición aséptica en lo ideológico y en lo político, que mantuvo a la profesión en una "dorada mediocridad". (AYLWIN. 1999:5).

11 GRASSI, Estela, La mujer y la profesión de asistente social. El control de la vida cotidiana. Hvmanitas, Buenos Aires, 1989. 
Sin embargo, la autora citada evidencia cómo la asignación de las funciones de "proteger, dirigir, educar, depurar a los demás» (que además exigían del «espíritu de sacrificio» y del «buen sentido») se reproducían en la propia formación, mediante las exigencias de personalidad y los requisitos ligados con las instancias alusivas a lo doméstico y lo cotidiano.

Las propuestas consignadas permiten aproximarnos a pensar la identidad profesional atendiendo al modo en el que la dimensión profesional resulta determinante en la manera que tiene un grupo profesional para autodescribirse en ciertas representaciones, que le permitan diferenciarse y comparar su práctica con la de otros grupos profesionales.

Y a su vez, como en esa dinámica la formación cumple un papel fundamental, en tanto ámbito donde el colectivo de profesionales construye «las suturas temporales», ${ }^{12}$ desde las cuales se solapan las ya nombradas confluencias, divergencias, pertenencias múltiples, apropiaciones y resistencias.

\section{Marcas de identidad en Trabajo Social}

De acuerdo con lo desarrollado en los párrafos precedentes, comprender la identidad como devenir y lo histórico como sustantivo de esa configuración ${ }^{13}$ habilita a reconocer los elementos que la hacen equivalente $y$, a la vez, que la definen como categoría oposicional.

En este sentido, los rasgos que caracterizan la construcción identitaria del Trabajo Social se manifiestan en un ritual de integración y desintegración, de caos y equilibrio, de herencias, transmisiones y recreaciones. $\mathrm{Al}$ respecto, vale hacer presente una reflexión de Teresa Matus ${ }^{14}$ acerca de la resignificación identitaria como manera de adentrarse en la responsabilidad de la herencia; herederos son aquellos que buscan respuesta a los

12 HALL, Stuart. Op. Cit. p. 6.

13 Véase LERA, Carmen; LUDI, Ma. Del Carmen; BUGDAHL, Susana; YOANNAS, Yamila, Identidad profesional de Trabajo Social. Principales rasgos de su configuración en distintos actores del campo profesional. Facultad de Trabajo Social UNER, Paraná, Entre Ríos. Recuperado de: http://www.fts. uner.edu.ar/secretarias/ext_inv/investigacion/proy_inv_vig/LERA_Identidad\%20profesional\%20 de\%20Trabajo\%20Social.pdf

14 Véase MATUS, Teresa en BUGDAHL, Susana, LERA, Carmen, LUDI, Carmen, "Desafíos Instituyentes sobre la cuestión identitaria del Trabajo Social en Argentina hoy", Año 15, N²3, 2015, ps. 95-101. 
desafíos del presente, se piensan y proyectan a partir de reelaboraciones históricas que las vinculan indisolublemente a generaciones anteriores.

En esa línea de reflexión, y de la interpretación de los datos empíricos obtenidos durante el proceso de la investigación, se ha podido identificar que el Trabajo Social tuvo y tiene rasgos que se vinculan con las ideas de vocación, las nociones de asistencia, las actividades de militancia, cuya impronta singulariza la trayectoria de la profesión en Santa Fe.

\section{Lo vocacional}

La discursividad que se ha instituido de forma hegemónica en Trabajo Social acerca de la idea de vocación ${ }^{15}$ encuentra su fundamento en las historiografías tradicionales, desde las cuales se refuerza la premisa evolutiva acerca del origen de la profesión - esto es, la continuidad de las actividades de caridad, beneficencia y filantropía. ${ }^{16}$

A propósito de ello, la investigación de Alicia Genolet ${ }^{17}$ constituye un aporte significativo para pensar "lo vocacional», en este caso, desde las trayectorias y voces de las primeras egresadas de la Escuela de Asistentes Sociales de Santa Fe.

Entre sus hallazgos acerca de la estructura del campo profesional, la autora citada postula a la vocación como uno de los elementos que reguló su funcionamiento. La vocación estaba unida al servicio, es decir, no era una actividad productiva, sino que su utilidad estaba ligada a la ayuda, al sacrificio, a la entrega. Asimismo, el compromiso marcaba un estilo de asumir la profesión, y se sustentaba en valores como la solidaridad, la cooperación y la entrega en relación con los otros. En ese contexto de posguerra, el ideal profesional desinteresado se asociaba con la idea de apostolado. Se requería de una dedicación tiempo completo, lo cual colisionaba con las

15 Los itinerarios que se fueron configurando acerca de "lo vocacional" — como "un llamado de Dios", "la misión de servir", "el elegido para..." - encontraron materialidad en los discursos de tinte religioso: "el mito de una vocación dada como objeto natural desde el llamado de otro parece garantizar en el psiquismo humano la presencia fehaciente de ese algo enigmático (...) que dispone el porvenir, capturado mediante nociones positivas tales como aptitudes, capacidad (...). (ROBLES. 2013:54).

16 MATUS, Teresa y otras. Op. Cit. p. 50.

17 GENOLET, Alicia, La problemática de la Asistencia Social en un contexto de cambios (de la crisis de 1930 al fin de la guerra). La experiencia de la Escuela de Asistentes Sociales de Santa Fe y sus primeras egresadas, Mimeo, Paraná, 2004. 
realidades familiares y los intereses particulares: «no se podía ser trabajador social y madre al mismo tiempo». ${ }^{18}$

Desde su perspectiva, la amplia presencia de mujeres se asociaba con ese ideal vocacional y con el perfil que se requería para el ejercicio de la profesión, es decir, para las tareas relacionadas al cuidado, la protección y la contención como extensión del rol maternal. ${ }^{19}$ En sintonía con sus planteos, Belén Lorente Molina ${ }^{20}$ analiza cómo el Estado a través de un discurso que fundamentaba que las actividades de cuidado y ayuda formaban parte del repertorio de contenidos simbólicos, materiales y prácticos de las culturas de género femeninas, reforzaba las vinculaciones entre las mujeres y las funciones que ellas realizaban como cuidadoras, pero también como miembros de profesiones gestoras de lo doméstico y de lo público.

\section{Las actividades de militancia}

En lo que respecta a las actividades de militancia en Trabajo Social, es preciso realizar algunas puntualizaciones para su abordaje. En principio, cabe aclarar que en este trabajo se hace referencia a la participación social, cultural, político-partidaria de las y los jóvenes en el ámbito de formación profesional de trabajadores sociales en Santa Fe (Capital).

Desde las indagaciones teóricas en torno al tema, Gustavo Papili ${ }^{21}$ expresa que entre los años 1958-1970 "el ingreso a la formación profesional llevaba a que por el entusiasmo por modificar una realidad "injusta", conceptualizada desde diferentes perspectivas, algunos opten por una militancia o adhesión política».22 No obstante, agrega que esta decisión no fue privativa del Trabajo Social, en tanto se condice con la dinámica de politización que vivió el país en esa década, motivo por el cual podría decirse que fue una característica generacional.

GENOLET, Alicia. Op. Cit. p. 109.

LORENTE MOLINA, Belén, "Género, ciencia y trabajo. Las profesiones feminizadas y las prácticas de cuidado y ayuda social" en ScriptaEthnologica, N² 26, 2004, ps. 39-53. Disponible en: http:// www.redalyc.org/pdf/148/14802602.pdf [búsqueda del 22 de enero del 2017].

21 PAPILI, Gustavo, El movimiento de Reconceptualización en la Escuela de Servicio Social de la ciudad de Santa Fe durante las décadas de 1960-1970, Mimeo, Paraná: Entre Ríos, 2009.

PAPILI, Gustavo Op. Cit. p. 173. 
A propósito de esa reflexión, Mario Sandoval ${ }^{23}$ al analizar la participación social y política actual de los jóvenes chilenos en el marco de los cambios culturales de fines de siglo conduce a pensar las actividades de militancia en relación con la conformación del modo de vivenciar «la juventud» y su imbricación con los contextos históricos.

En este sentido, Nancy Palacios Mena y José Herrera González ${ }^{24}$ aportan la categoría subjetividad política ${ }^{25}$ como dimensión de análisis, la cual habilita a pensar las maneras en que las y los jóvenes se asumen y construyen como sujetos políticos - esto es, el desarrollo de la capacidad de sentir, pensar, expresar y actuar políticamente desde lo individual y lo colectivo-, y la preponderancia que este proceso adquiere en la formación como ámbito de socialización política. ${ }^{26}$

Desde esa perspectiva, la universidad al igual que la escuela de hoy en crisis y trasformación-, en tanto escenario de construcción de subjetividad, producción de socialización política y demanda de derechos, se convierte en un contexto y fuente de prácticas políticas. En otros términos, la configuración de la subjetividad en estos lugares constituye la posibilidad de construcción de sujetos comprometidos y con capacidad de acción.

\section{La Asistencia}

Por otra parte, entendiendo que la asistencia representa una dimensión que ha legitimado el desarrollo del Trabajo Social en su devenir histórico, interesa puntualizar en el reconocimiento de algunos elementos subyacentes en sus interpretaciones para establecer mediaciones conceptuales con las apreciaciones expresadas por las estudiantes.

23 SANDOVAL, Mario. (s/f). "La relación entre los cambios culturales de fines de siglo y la participación social y política de los jóvenes". En: La participación social y política de los jóvenes en el horizonte del nuevo siglo. Disponible en: biblioteca.clacso.edu.ar/ar/libros/cyg/juventud/Sandoval

24 PALACIOS-MENA, Nancy, HERRERA-GONZALES, José, "Subjetividad, socialización política y derechos en la escuela” en Revista Internacional de Investigación en Educación. Año 5, № 11, 2013, ps. 413-437.

25 Los autores postulan que la subjetividad política refiere a las percepciones, representaciones, ideas, sentimientos, expectativas, deseos que orientan las prácticas sociales de los sujetos en un contexto determinado. (PALACIOS-MENA y HERRERA-GONZÁLEZ, 2013:418).

26 Concebir la formación profesional como ámbito de socialización política, supone considerar que toda concepción, perspectiva y práctica social que pueda ser caracterizada como política en ese contexto, es producto de un aprendizaje; y en cuanto tal, refiere al conjunto de procesos mediante los cuales se construyen y configuran los aspectos directamente asociados con el modo en que las personas se organizan y participan de los asuntos públicos. (PALACIOS-MENA y HERRERAGONZÁLEZ, 2013. 432). 
En primer lugar, es necesario pensar cómo se ha ido configurando históricamente el espacio de lo socioasistencial, lo cual implica reconocer los procesos ${ }^{27}$ que dieron lugar a la voluntad política del Estado de crear un agente especializado en abordar las emergentes manifestaciones de la denominada cuestión social, en articulación con las políticas sociales.

Otro elemento relevante se relaciona con la demarcación de los sujetos «destinatarios» de la intervención estatal. Carmen Lera ${ }^{28}$ señala que las distintas tipologías ${ }^{29}$ que se fueron construyendo frente a la problemática de la asistencia ponen foco sobre el destinatario y no sobre las situaciones, lo cual no es inocente, sino que tiende a deshistorizar y descontextualizar las condiciones de producción de las mismas.

En un encuadre teórico similar, Alicia Genolet identifica cómo desde la formación académica de época se planteaba la necesidad de formar profesionales cuya tarea consistía en asimilar a los individuos y familias al medio, desde una idea de control de policía ${ }^{30}$ sobre los sectores pobres.

La vigencia de dichos postulados se expresa, a su vez, en la formulación de programas focalizados y territorializados impulsados por la oleada neoliberal. La propuesta de focalización implica definir «la población objetivo» de cada uno de los programas, es decir, determinar quiénes son los merecedores.

En esta línea, reflexionar acerca de las lógicas que atraviesan estas perspectivas constituye una apuesta para el Trabajo Social porque, tal como se ha expuesto, en el escenario contemporáneo nos encontramos frente a propuestas de políticas sociales asistenciales, que recaen sobre los sujetos desdibujando las relaciones y procesos propios de la sociedad de mercado. A este imperativo cabe agregar la necesidad de resignificar los

27 Asimismo, es ineludible analizar estos procesos en autonomía con los modelos de Estado y de Desarrollo, tanto como de las fuerzas sociales que los moldean.

28 LERA, Carmen, Intervenciones profesionales y dimensión asistencial. Problematizaciones urgentes desde Trabajo Social. EDUNER, Paraná- Entre Ríos, 2015.

29 En el recorrido histórico referido al surgimiento de la profesión de Trabajo Social en Argentina, Carmen Lera evidencia cómo las visiones dominantes de época fueron sedimentando las estructuras e instituciones de la asistencia social, que se nucleaban en la idea de "regeneración del caído", es decir, darle al sumergido lo que necesita y de acuerdo con su necesidad.

30 En correlato con esta idea, Estela Grassi plantea que históricamente la asistencia social ha tenido con mayor o menor magnitud un cliente vergonzante. También señala, el desarrollo de cierta actitud de sospecha por parte de los profesionales de la asistencia hacia los destinatarios de dichas políticas, desde la presunción de estar frente a potenciales abusadores aprovechadores de los beneficios. 
debates históricos acerca de la dimensión asistencial en la profesión, revisando las concepciones y tendencias hegemónicas en el tratamiento de la tensión derecho-ayuda.

Es pertinente introducir algunas consideraciones que habilitan a pensar ¿de qué hablamos cuando hablamos de asistencia? Aldaíza Sposati ${ }^{31}$ señala que una de las principales características de la asistencia social es que se define como campo no-mercantil, asociándose con la idea de que está dirigida sólo a aquellas personas que no la pueden pagar: los pobres. Al constituirse principalmente como una ayuda, el campo de la asistencia social se expresa como de no-derecho y, por tal, no se la ve como un campo de saberes, sino que se la liga a prácticas de beneficencia y caridad, de carácter intuitivo y moral.

\section{Puntos de partida para pensar los rasgos identitarios de Trabajo Social}

El interés por conocer el tema de la Identidad Profesional en Trabajo Social llevó a profundizar sobre los rasgos que caracterizan esa construcción. En esa búsqueda, los aportes de las estudiantes que participaron del cuestionario autoadministrado, como aquellas que fueron entrevistadas, permitieron el acercamiento al objeto de estudio de manera situada y contextualizada.

Al abordar los relatos de las entrevistadas cobró relevancia el análisis de las trayectorias en su singularidad; por ello, en el trabajo de campo se pretendió reconstruir los rasgos identitarios de Trabajo Social desde las experiencias de las estudiantes que cursaron el quinto año de la carrera durante 2016, entendiendo que en su propia narratividad se manifiestan las valoraciones, los sentidos y contenidos peculiares sobre la profesión.

Por otra parte, el trabajo de análisis constituyó un desafío para "pensar desde lo propio ${ }^{32}$ los rasgos identitarios de Trabajo Social en la singularidad de la formación profesional en Santa Fe. Para analizar el contenido de las respuestas que implicaron la reflexión «desde el presente» - sobre ideas previas, hechos significativos, entre otros-se procuró no perder de

31 LERA, Carmen. Op. Cit. p. 180.

32 Expresión tomada de ZEMELMAN, Hugo, Configuraciones críticas. Pensar epistémico sobre la realidad, Siglo XXI Editores-Centro de la Cooperación Regional para la educación de adultos en América Latina y el Caribe (CREFAL), México, 2011. 
vista los atravesamientos, mediaciones de las memoria $(\mathrm{s})^{33}$ y de la propia formación inclusive. En este sentido, también se consideró el concepto de habitus lingüístico ${ }^{34}$ de las estudiantes entrevistadas.

En la trama que pudo construirse a partir del cruce de la información obtenida y teniendo en cuenta las categorías centrales de la investigación, se destacan como ejes de análisis para acercar al objeto de estudio los siguientes:

- Los relatos en relación con el reconocimiento social del Trabajo Social que involucran las ideas previas de las estudiantes e imaginarios sobre la profesión.

- Huellas identitarias del Trabajo Social, en alusión a la vocación como modeladora del perfil profesional «feminizado»; las actividades de militancias en y de Trabajo Social; la asistencia.

- El lugar de la formación en la configuración de la identidad. La producción de nuevos sentidos y contenidos.

- La intervención profesional en relación con el posicionamiento éticopolítico, crítico.

En esta línea, el análisis del material empírico permitió reconocer algunos rasgos identitarios de la profesión, en la dinámica de lo atribuidolo asumido y la producción-reproducción de representaciones e imaginarios. A partir de las ideas previas que las estudiantes tenían sobre la profesión, sus motivaciones al momento de elegir la carrera, las opiniones de sus entornos más próximos, fue posible identificar una imagen signada por un perfil «asistencialista» vinculada con una práctica paliativa, y una imagen ligada con un rol «revolucionario» asociada con la idea de prácticas transformadoras.

Los aportes de algunas autoras citadas ${ }^{35}$ habilitan a profundizar sobre la construcción de estas imágenes en la trayectoria de la profesión. De la recuperación teórica se puede reconocer que durante el denominado

33 Se habla de memoria (s) en plural, ya que no existe posibilidad de realización de una memoria neutral. Más que una reflexión teórica es un ejercicio, una práctica signada políticamente. (CALVEIRO, 2006:11).

34 El habitus es simultáneamente productor de prácticas sociales simbólicas e ideológicas construyendo una gramática generadora de prácticas, mediadora entre las relaciones socialmente objetivas y los comportamientos individuales, producto, a su vez también, de la interiorización de las condiciones objetivas y de las estrategias de adaptación de los actores a un campo. (ALONSO, 2002:125).

35 Nidia Aylwin, y Estela Grassi ubican al Movimiento de Reconceptualización como proceso que contribuyó al cuestionamiento -en términos descalificadores- del quehacer profesional. 
Movimiento de Reconceptualización se esbozaron algunos elementos que contribuyeron a la definición de una identidad devaluada - considerando las prácticas de asistencia como expresión de un Trabajo Social «tradicional»- y una identidad positiva —-donde los ideales de revolución se constituyeron como elementos superadores de la anterior.

Contemplando las voces de las entrevistadas se visualiza la presencia de algunos de estos elementos en la actualidad, en tanto en sus relatos hicieron referencia a "ayudar», "trabajar con la gente pobre», "generar alguna transformación social», "tener amor por los otros», "entregar cosas», «combatir la pobreza», entre otros.

Sin embargo, las estudiantes reelaboran estas ideas al plantear que la vigencia de dichas imágenes se corresponde con algunas prácticas profesionales desde las cuales se da entidad a esas versiones «erróneas» sobre la profesión. También, enfatizan en la falta de disputa colectiva y en la responsabilidad individual de cada profesional como factores que coadyuvan a reproducirlas.

En base a estas consideraciones, coincidieron al enunciar el proceso de la formación profesional como instancia significativa para replantear y llenar de contenido sus ideas previas sobre «la profesión»; «la realidad»; «los sujetos»; «las políticas sociales». En una primera mirada, podría pensarse que la formación, en tanto proceso colectivo de interacción que permite la diferenciación o identificación de los grupos profesionales en cuanto a su ser y quehacer profesional, ${ }^{36}$ juega un papel fundamental en la construcción y sostenimiento del núcleo identitario profesional.

Según sus perspectivas, la formación profesional se piensa como instancia de replanteo constante y de revisión crítica respecto de las prácticas y de los contenidos aprehendidos durante el proceso. Esto se ratifica en las recuperaciones que hicieron acerca de los temas trabajados, las discusiones desarrolladas en distintos espacios, las experiencias de prácticas preprofesionales.

Cabe agregar que desde las distintas instancias mencionadas, pareciera prevalecer la necesidad de generar procesos de enseñanza-aprendizaje sustentados en fuertes argumentaciones y problematizaciones sobre las condiciones de existencia de las/los sujetos. A partir de esas ideas, resulta posible pensar la formación profesional como «imperativo ético» ${ }^{37} \mathrm{y}$, por

36 MACHUCA BARBOSA, Adriana. Op. Cit. p. 49.

37 Véase CAZZANIGA, Susana, Hilos y nudos. La formación, la Intervención y lo político en el Trabajo Social, Espacio Editorial, Buenos Aires: Argentina, 2007. 
tal, como estrategia para sostener una identidad «basada en la defensa irrestricta de los derechos humanos-ciudadanos y el respeto por la dignidad de la persona». ${ }^{38}$

A su vez, si se observa retrospectivamente, y considerando los estu$\operatorname{dios}^{39}$ que abordan la trayectoria de la profesión y de la formación profesional en la singularidad del entramado santafesino, podría pensarse que el trabajo crítico se mantiene como rasgo significativo en Trabajo Social.

En este núcleo de problematización, las estudiantes también aludieron a la reformulación de ideas vinculadas a la "ayuda», "asistencia» y a lo «vocacional». Concomitante, y de acuerdo con el corpus teórico del trabajo, las ideas de vocación, las actividades de militancia, y las nociones de ayuda, se constituyen - en términos diacrónicos ${ }^{40}$ - como «huellas identitarias» que han marcado a la profesión en su devenir histórico.

En relación con lo vocacional, si bien no es posible plantear líneas de continuidad con las significaciones que las pioneras atribuyeron a dicha dimensión durante la consolidación del campo profesional en la provincia de Santa Fe, en los relatos de las estudiantes se identifican algunos matices alusivos a las ideas de "compromiso con el otro", el tiempo de "dedicación», "valores de entrega y responsabilidad» como forma característica de ejercer la profesión, en la actualidad.

Por otro lado, se ha podido notar que el tema de la militancia de y en Trabajo Social evoca una especie de contradicción. Desde la breve indagación teórica, vale recuperar las actividades de militancia -como expresión de los valores de justicia/solidaridad, compromiso/transformaciónen función de diferenciarla con lo que ha sido un trabajo social aséptico, tecnológico, en la historia de la profesión. Sin embargo, en las opiniones de las estudiantes, cabe marcar cierta reticencia a pensar la militancia cultural, política y social de la mano de la intervención profesional; en tanto pareciera necesario diferenciarlas, como pertenecientes a distintos espacios, para no perder «objetividad profesional».

TRAVI, Bibiana, "Investigación histórica e identidad en trabajo social. Nuevas y renovadas epistemologías para los nuevos tiempos" en Revista del Departamento de Ciencias Sociales, № 5, 2014, ps. 37-58. Disponible en: http://www.redsocialesunlu.net/wp-content/uploads/2014/11/ RSOC005-03-Investigaci\%C3\%B3n-historica-e-identidad-en-trabajo-social-TRAVI.pdf [búsqueda del 27 de junio de 2016]

39 Puntualmente, se hace referencia a la tesis de maestría de GENOLET, Alicia, Op. Cit. p. 1-125; y PAPILI, Gustavo, Op, Cit. p. 1-222.

40 Lo que la profesión tiene en términos de permanencia, de lo que ha resistido al pasaje del tiempo desde su instauración y desde los cambios que han operado en su trayectoria histórica. (MELANO, 2007:89). 
En otra línea de reflexión, se han involucrado algunas lecturas que significan la dimensión asistencial como rasgo que caracteriza al Trabajo Social. No obstante, también se expresa como tema controversial en las enunciaciones de las estudiantes. Se ha podido observar cierto reparo, en tanto pareciera que relacionan las ideas de ayuda y asistencia con la entrega sistemática de recursos materiales. Asimismo, es posible notar que vinculan estas prácticas con aquellas representaciones que sitúan a la profesión como evolución de las actividades de caridad, beneficencia y filantropía. No obstante, según el planteo de una de las entrevistadas, también la ayuda es pensada como un acompañamiento, un «brindar herramientas». Por lo que es posible señalar que esta noción también aparece desde una mirada más amplia y superadora de la relación ayuda-recurso material.

En este sentido, y a modo de apreciación personal, se concluye en que es relevante insistir en la revisión y discusión contextualizada en un presente de los valores y principios sobre los cuales se erigió la profesión.

Continuando con la identificación de los rasgos "permanentes» que definen la Identidad Profesional del Trabajo Social, se hizo mención al tema de la intervención profesional y al posicionamiento ético-político, ya que fueron mayormente enunciados por las estudiantes como palabras clave y significativas para la profesión. Este dato objetivo sintoniza con los planteos de Nora Aquín ${ }^{41}$ respecto de entender a la intervención profesional — con el propósito de transformar o estabilizar cierto aspecto de la realidad social- como el «núcleo duro» de la identidad del Trabajo Social.

En relación con este aporte, y según lo conversado con las estudiantes, es posible observar que los rasgos que caracterizan a la profesión en tanto praxis social refieren al lazo histórico que une el Trabajo Social y los derechos humanos. Y en la línea de lo planteado por Carlos Eroles, ${ }^{42}$ los lazos ético-políticos presentes en el compromiso que el trabajador social ha sostenido históricamente con el "otro excluido», serían un elemento reconocido como indispensable en la configuración de la identidad profesional en el contexto actual.

41 AQUÍN, Nora, "Hacia la construcción de enfoques alternativos para el Trabajo Social para el nuevo milenio" en Revista de Servicio Social, Vol. 1, № 3, junio de 1999, p. 9.

42 EROLES, Carlos, "¿Qué implica la profesionalización del Trabajo Social en el contexto de las transformaciones sociales, políticas, económicas y culturales?" en ROZAS PAGAZA, Margarita (coord.), La profesionalización en trabajo social. Rupturas y continuidades, de la reconceptualización a la construcción de proyectos ético-políticos, Espacio Editorial, 2007, España, p. 154. 
Otro rasgo identitario presente en los relatos de las entrevistadas se relaciona con pensar el espacio público-estatal como un espacio privilegiado para el ejercicio profesional, ya que habilita a «hacer público lo social»; no planteado como único espacio, ya que reconocen también al privado, pero sí como una línea de continuidad de lo identitario en cuanto al compromiso con lo público.

La construcción que se ha elaborado sobre los rasgos identitarios de la profesión a partir de los relevos teóricos y de las apreciaciones de las estudiantes está signada por la heterogeneidad en la que habitan múltiples experiencias. En este entramado, se han planteado algunas incipientes reflexiones, que si bien se corresponden con núcleos de análisis que no son nuevos - en tanto el tema ha preocupado históricamente al colectivo profesional y muchas producciones reflejan esta inquietud- se considera que a la luz del presente pueden dar lugar a renovadas e innovadoras problematizaciones.

\section{Referencias bibliográficas}

ALONSO, L. "Los mercados lingüísticos o el muy particular análisis sociológico de los discursos de Pierre Bourdieu". Estudios de Sociolingüística. Vol. 1, №3, 2002, ps. 111-131.

AQUÍN, N. "Hacia la construcción de enfoques alternativos para el Trabajo Social para el nuevo milenio". Revista de Servicio Social, Vol. 1, № 3, junio de 1999, ps. 13-18.

AYLWIN, N. "Identidad e historia profesional". Revista Colombiana de Trabajo Social, № 13, 1999, ps. 1-12. Disponible en: HYPERLINK "http://www.ts.ucr. ac.cr/binarios/congresos/reg/slets/ slets-016-103.pdf" http://www.ts.ucr. ac.cr/binarios/congresos/reg/slets/ slets-016-103.pdf [búsqueda del 28 de noviembre de 2016].
CALVEIRO, P. (2005). Política y/o violencia. Una aproximación a la guerrilla de los años 70. Buenos Aires, Argentina: Grupo Editorial Norma.

CAZZANIGA, S. (2007). Hilos y nudos. La formación, la Intervención y lo político en el Trabajo Social. Buenos Aires, Argentina: Espacio Editorial.

CIFUENTES, M.R. (2012). "Identidad y formación en Trabajo Social». En AA. VV. Naturaleza desafíos y perspectivas contemporáneas de la intervención en Trabajo Social. Memorias I. Seminario Internacional. Buenos Aires: Argentina: Lumen.

DUBAR, C. "El Trabajo y las identidades profesionales y personales". Revista Latinoamericana de Estudios del Trabajo, Año 7, №13, 2001, ps. 5-16. 
(2002). La crisis de las identidades. La interpretación de una mutación. Barcelona, España: Ediciones Bellaterra.

DUBET, F. "De la sociología de la identidad a la sociología del sujeto". Estudios sociológicos, VII, N²1, 1989, ps. 519- 545.

EROLES, C. (2007). "¿Qué implica la profesionalización del Trabajo Social en el contexto de las transformaciones sociales, políticas, económicas y culturales?». En ROZAS PAGAZA, M. (coord.), La profesionalización en trabajo social. Rupturas y continuidades, de la reconceptualización a la construcción de proyectos ético-políticos. España: Espacio Editorial.

GENOLET, A. (2004). La problemática de la Asistencia Social en un contexto de cambios (de la crisis de 1930 al fin de la guerra). La experiencia de la Escuela de Asistentes Sociales de Santa Fe y sus primeras egresadas. Mimeo. Paraná, Entre Ríos.

GENOLET, A.; LERA, C.; GELSI, M.C.; MUSSO, S. y SCHOENFELD, Z. (2005). La profesión de Trabajo Social ¿cosa de mujeres? Estudio sobre el campo profesional desde la perspectiva de los trabajadores sociales. Buenos Aires, Argentina: Espacio Editorial.

GRASSI, E. (1989). La mujer y la profesión de asistente social. El control de la vida cotidiana. Buenos Aires, Argentina: Hvmanitas.

HALL, S. (2011). "¿Quién necesita "identidad"?». En HALL, Stuart, DU GAY, Paul, (comp.) Cuestiones de Identidad Cultural. $2^{\mathrm{a}}$. Edición. Buenos Aires, Argentina: Amorrortu.
LERA, C.; LUDI, M. Del C.; BUGDAHL, S. y YOANNAS, Y. Identidad profesional de Trabajo Social. Principales rasgos de su configuración en distintos actores del campo profesional. Facultad de Trabajo Social UNER, Paraná, Entre Ríos. Recuperado de:

http://www.fts.uner.edu.ar/secretarias/ ext_inv/investigacion/proy_inv_vig/ LERA_Identidad\%20profesional\%20 de\%20Trabajo\%20Social.pdf

LERA, C. (2015). Intervenciones profesionales y dimensión asistencial. Problematizaciones urgentes desde Trabajo Social. Paraná, Entre Ríos: EDUNER.

LORENTE MOLINA, B. " Género, ciencia y trabajo. Las profesiones feminizadas y las prácticas de cuidado y ayuda social». ScriptaEthnologica, N²6, 2004, ps. 39-53. Disponible en: http://www. redalyc.org/pdf/148/14802602.pdf [búsqueda del 22 de enero del 2017].

MACHUCA BARBOSA, A. (2008). "La identidad profesional de los sociólogos. Una perspectiva teórico-metodológica". En MACHUCA BARBOSA, Adriana, La identidad profesional de los sociólogos (tesis de maestría). Sede Académica Flacso, México.

MATUS, T. "Reflexiones en torno a una Ética de la Intervención Social». Perspectivas, $N^{\circ}$ 9, 2000. Santiago, Chile: UCSH, ps. 17- 32 .

MATUS, T.; AYLWIN, N. y FORTTES, A. (2004). La reinvención de la memoria. Indagación sobre el proceso de profesionalización del Trabajo Social chileno 1925-1965. Santiago de Chile: Pontifi- 
cia Universidad Católica de Chile, Facultad de Ciencias Sociales. Escuela de Trabajo Social.

MELANO, C. (2012) "Los retos de la intervención profesional en el contexto latinoamericano". En AA. VV. Naturaleza desafíos y perspectivas contemporáneas de la intervención en Trabajo Social. Memorias I. Seminario Internacional. Buenos Aires, Argentina: Lumen.

PALACIOS-MENA, N. y HERRERA-GONZALES, J. "Subjetividad, socialización política y derechos en la escuela". Revista Internacional de Investigación en Educación. Año 5, N¹1, 2013, ps. 413-437.

PAPILI, G. (2009). El movimiento de Reconceptualización en la Escuela de Servicio Social de la ciudad de Santa Fe durante las décadas de 1960-1970. Mimeo, Paraná, Entre Ríos.

ROBLES, C. Trabajo Social como elección profesional. Buenos Aires: Espacio.
SANDOVAL, Mario. (s/f). La relación entre los cambios culturales de fines de siglo y la participación social y política de los jóvenes. En: La participación social y política de los jóvenes en el horizonte del nuevo siglo. Disponible en: biblioteca.clacso.edu.ar/ar/libros/cyg/juventud/Sandoval

TRAVI, Bibiana, "Investigación histórica e identidad en trabajo social. Nuevas y renovadas epistemologías para los nuevos tiempos" en Revista del Departamento de Ciencias Sociales, $N^{\circ} 5$, octubre 2014, ps. 37-58. Disponible en: http://www.redsocialesunlu.net/wpcontent/uploads/2014/11/RSOC00503-Investigaci\%C3\%B3n-historica-eidentidad-en-trabajo-social-TRAVI.pdf [búsqueda del 27 de junio de 2016].

ZEMELMAN, Hugo, Configuraciones críticas. Pensar epistémico sobre la realidad, Siglo XXI Editores - Centro de la Cooperación Regional para la educación de adultos en América Latina y el Caribe (CREFAL), México, 2011. 


\section{Melina Chechele}

Estudiante avanzada de la Licenciatura

en Trabajo Social y Cientibecaria por el

Programa de Becas de Iniciación a la Inves-

tigación para estudiantes de Carreras de

Grado, Universidad Nacional del Litoral. Par-

ticipante como voluntaria del CAID 2016:

"La profesionalización de la Asistencia

Social. Santa Fe en el segundo tercio del

siglo XX". Participante en el proyecto de ex-

tensión "Hacia la autonomía y participación

social de las personas con discapacidad".

\section{REGISTRO BIBLIOGRÁFICO}

Melina Chechele

"APUNTES PRELIMINARES PARA DESANDAR LOS RASGOS IDENTITARIOS DE TRABAJO

SOCIAL", en Papeles del Centro de Investigaciones, Facultad de Ciencias Jurídicas

y Sociales, UNL, publicación semestral, año 7, número 18, Santa Fe, República

Argentina, 2017, pp. 47-64. 